\title{
Influences of Duration of Inspiratory Effort, Respiratory Mechanics, and Ventilator Type on Asynchrony With Pressure Support and Proportional Assist Ventilation
}

\author{
Renata S Vasconcelos MSc, Raquel P Sales MSc, Luíz H de P Melo MSc, \\ Liégina S Marinho MSc, Vasco PD Bastos PhD, Andréa da NC Nogueira MSc, \\ Juliana C Ferreira PhD, and Marcelo A Holanda PhD
}

\begin{abstract}
BACKGROUND: Pressure support ventilation (PSV) is often associated with patient-ventilator asynchrony. Proportional assist ventilation (PAV) offers inspiratory assistance proportional to patient effort, minimizing patient-ventilator asynchrony. The objective of this study was to evaluate the influence of respiratory mechanics and patient effort on patient-ventilator asynchrony during PSV and PAV plus (PAV+). METHODS: We used a mechanical lung simulator and studied 3 respiratory mechanics profiles (normal, obstructive, and restrictive), with variations in the duration of inspiratory effort: 0.5 , 1.0, 1.5, and 2.0 s. The Auto-Trak system was studied in ventilators when available. Outcome measures included inspiratory trigger delay, expiratory trigger asynchrony, and tidal volume $\left(\mathrm{V}_{\mathrm{T}}\right)$. RESULTS: Inspiratory trigger delay was greater in the obstructive respiratory mechanics profile and greatest with a effort of $2.0 \mathrm{~s}(160 \mathrm{~ms})$; cycling asynchrony, particularly delayed cycling, was common in the obstructive profile, whereas the restrictive profile was associated with premature cycling. In comparison with PSV, PAV+ improved patient-ventilator synchrony, with a shorter triggering delay (28 ms vs $116 \mathrm{~ms})$ and no cycling asynchrony in the restrictive profile. $V_{T}$ was lower with PAV+ than with PSV $(630 \mathrm{~mL}$ vs $837 \mathrm{~mL}$ ), as it was with the single-limb circuit ventilator $(570 \mathrm{~mL}$ vs $837 \mathrm{~mL})$. PAV+ mode was associated with longer cycling delays than were the other ventilation modes, especially for the obstructive profile and higher effort values. Auto-Trak eliminated automatic triggering. CONCLUSIONS: Mechanical ventilation asynchrony was influenced by effort, respiratory mechanics, ventilator type, and ventilation mode. In PSV mode, delayed cycling was associated with shorter effort in obstructive respiratory mechanics profiles, whereas premature cycling was more common with longer effort and a restrictive profile. PAV+ prevented premature cycling but not delayed cycling, especially in obstructive respiratory mechanics profiles, and it was associated with a lower $\mathbf{V}_{\mathbf{T}}$. Key words: artificial respiration; respiratory mechanics; COPD; ARDS; mechanical ventilators. [Respir Care 2017;62(5):550-557. (C) 2017 Daedalus Enterprises]
\end{abstract}

Introduction

Patient-ventilator asynchrony is a mismatch between the inspiratory and expiratory times of the patient and those of

\footnotetext{
Ms Vasconcelos, Ms Sales, Mr Melo, Ms Marinho, Dr Bastos, Ms Nogueira, and Dr Holanda are affiliated with the Federal University of Ceará, Fortaleza, Brazil. Dr Ferreira is affiliated with the University of São Paulo School of Medicine, São Paulo, Brazil.

The authors have disclosed no conflicts of interest.

Supplementary material related to this paper is available at http:// www.rcjournal.com.
}

the mechanical ventilator, and it is common during assisted ventilation. ${ }^{1-3}$ Patient-ventilator asynchrony is associated with complications such as prolonged mechanical ventilation and increased mortality, although it is unclear whether that is a cause-and-effect relationship..$^{3,4}$

\footnotetext{
Correspondence: Renata Santos Vasconcelos MSc, Respiration Laboratory, Center for Biomedicine, Federal University of Ceará (UFC), Av. Borges de Melo, 1120 apto 402 Fátima, Fortaleza - Ceará 60.415-510, Brazil. E-mail: renatavasconcelos23@gmail.com.
}

DOI: $10.4187 /$ respcare. 05025 
Pressure support ventilation (PSV) is a spontaneous mode of ventilation frequently used during the weaning phase because it allows the patient to influence the duration of inspiratory time and ventilatory assistance. ${ }^{5,6}$ However, clinical studies have shown that PSV can result in respiratory distress and patient-ventilator asynchrony. ${ }^{1,7}$

Proportional assist ventilation (PAV) is a ventilatory mode in which the ventilator generates assistance instantaneously and proportional to the effort of the patient, functioning as an amplifier of inspiratory effort and giving the patient greater control over breathing patterns, including tidal volume $\left(\mathrm{V}_{\mathrm{T}}\right)$, duration of inspiration and expiration, and flow delivery. ${ }^{8,9} \mathrm{In}$ its more recent version, it is known as PAV plus (PAV+), which automatically estimates the mechanics of the respiratory system and autoadjusts ventilatory support. Previous studies have shown that $\mathrm{PAV}+$ mode improves patient-ventilator synchrony more than do conventional modes, such as PSV. ${ }^{10,11}$ However, cycling off in PAV + mode employs user-set fixed criteria, which can influence patient-ventilator synchrony. ${ }^{12}$

It is believed that the respiratory mechanics of the patient is one of the factors that influences triggering and cycling in the ventilator. ${ }^{13-15}$ However, it is unknown how changes in airway resistance, static compliance of the respiratory system, and the interaction between the two during respiratory muscle contraction affect the degree of patient-ventilator asynchrony in the PSV and PAV + modalities. ${ }^{16-18}$

We hypothesized that respiratory mechanics and the duration of inspiratory effort would significantly affect patient-ventilator interaction in PSV and PAV + modes. The aim of this study was to evaluate the influence of respiratory mechanics and duration of inspiratory muscle effort on patient-ventilator asynchrony during PSV and PAV+ ventilation for different models of mechanical ventilators.

\section{Methods}

\section{Study Design}

This was an experimental study conducted in the Respiration Laboratory of the Department of Internal Medicine at the Federal University of Ceará in Fortaleza, Brazil.

\section{Lung Model}

A mechanical model of realistic simulation of mechanical ventilation asynchrony was used. We employed a lung simulator (ASL 5000, IngMar Medical, Pittsburgh, Pennsylvania), simulating predefined combinations of 3 respiratory mechanics profiles and 4 different effort values. ${ }^{19}$

The 3 respiratory mechanics profiles were normal, obstructive, and restrictive. ${ }^{17,20,21}$ The profiles studied are

\section{QUICK LOOK}

\section{Current knowledge}

Patient-ventilator synchrony is a challenge in mechanical ventilation and is associated with complications. Pressure support ventilation is often associated with patient-ventilator asynchrony. Proportional assist ventilation plus offers inspiratory assistance proportional to patient effort.

\section{What this paper contributes to our knowledge}

In a lung model study, we demonstrated that mechanical ventilation asynchrony was influenced by the duration of respiratory muscle effort, respiratory mechanics, ventilator type, and ventilation mode. In pressure support ventilation mode, delayed cycling was more common with shorter efforts in the obstructive respiratory mechanics profile, whereas premature cycling was more common with longer efforts in the restrictive profile. The performance of a single-limb circuit portable ventilator was similar to that of conventional ICU ventilators. These patterns of asynchrony were also present in proportional assist ventilation plus mode, although to a lesser degree.

shown in Table 1 . The respiratory muscle pressure $\left(\mathrm{P}_{\text {mus }}\right)$ was set at $-7.5 \mathrm{~cm} \mathrm{H}_{2} \mathrm{O}$, and 4 effort values were configured by using the ASL 5000 software: 0.5, 1.0, 1.5, and $2.0 \mathrm{~s}$. Therefore, the initial inspiration effort was the same for all inspiratory times. This was done to avoid variations in the buildup to the pressure drop or flow that triggers the ventilator. The airway occlusion pressure at $0.1 \mathrm{~s}$ was kept constant at $-2.5 \mathrm{~cm} \mathrm{H}_{2} \mathrm{O}$ in all simulations. Consequently, there were 12 scenarios resulting from the combination of 3 respiratory mechanics profiles and 4 effort values. To avoid artifacts and ensure reproducible results, the simulation setup was dismantled and rebuilt at least 4 times in all sets of experiments for each ventilator.

\section{Mechanical Ventilators}

Two types of mechanical ventilators were studied: ICU ventilators with dual-limb circuits (Esprit V1000 [Philips Respironics, Murrysville, Pennsylvania]; DX 3012 [Dixtal, Buenos Aires, Argentina]; Evita IV [Dräger, Lübeck, Germany]; Servo-i [Maquet, Solna, Sweden]; and Puritan Bennett 840 [Covidien, Mansfield, Massachusetts]) and a single-limb circuit portable ventilator (Trilogy 100, Philips Respironics). No external humidification system was used. To reproduce the situation of an intubated adult ICU patient, the mechanical ventilators were connected 


\section{Influence of Simulated Variables on Asynchrony in PSV and PAV}

Table 1. Configuration of the Parameters of the Lung Simulator According to the Respiratory Mechanics Profile

\begin{tabular}{lcrcr}
\hline \hline \multirow{2}{*}{ Profile } & $\begin{array}{c}\text { Compliance } \\
\left(\mathrm{mL} / \mathrm{cm} \mathrm{H}_{2} \mathrm{O}\right)\end{array}$ & $\begin{array}{c}\text { Resistance } \\
\left(\mathrm{cm} \mathrm{H}_{2} \mathrm{O} / \mathrm{L} / \mathrm{s}\right)\end{array}$ & $\begin{array}{c}\text { Expiratory } \\
\left(\mathrm{cm} \mathrm{H}_{2} \mathrm{O} / \mathrm{L} / \mathrm{s}\right)\end{array}$ & $\begin{array}{c}\text { Frequency } \\
\text { (cycles/min })\end{array}$ \\
\hline Normal & 60 & 3 & 3 & 15 \\
Obstructive & 80 & 10 & 20 & 12 \\
Restrictive & 30 & 8 & 8 & 15 \\
\hline
\end{tabular}

to the ASL 5000 simulator using an $8.0-\mathrm{mm}$ endotracheal tube. ${ }^{16}$

All of the ventilators were calibrated and configured in PSV mode, except the Trilogy ventilator, which was set to spontaneous mode. Ventilator parameters were set according to the respiratory mechanics profiles, as follows ${ }^{1,22}$ : for the restrictive profile, a PEEP of $10 \mathrm{~cm} \mathrm{H}_{2} \mathrm{O}$, pressure support of $13 \mathrm{~cm} \mathrm{H}_{2} \mathrm{O}$, and an expiratory trigger of $25 \%$ of peak inspiratory flow; for the normal profile, a PEEP of $5 \mathrm{~cm} \mathrm{H}_{2} \mathrm{O}$, pressure support of $15 \mathrm{~cm} \mathrm{H}_{2} \mathrm{O}$, and an expiratory trigger of $25 \%$ of peak inspiratory flow; and for the obstructive profile, a PEEP of $5 \mathrm{~cm} \mathrm{H}_{2} \mathrm{O}$, pressure support of $15 \mathrm{~cm} \mathrm{H}_{2} \mathrm{O}$, and an expiratory trigger of $45 \%$ of the peak inspiratory flow. The PAV + mode is available only on the Puritan Bennett 840 ventilator. The percentage of support was adjusted to achieve the same mean airway pressure obtained previously in the PSV mode of the same ventilator, and the expiratory flow trigger was set to $3 \mathrm{~L} / \mathrm{min}$, as recommended by the manufacturer. ${ }^{5}$

The Trilogy ventilator was used to study the performance of its digital Auto-Trak system for the inspiratory and expiratory trigger. The Auto-Trak system consists of a technology capable of automatically adjusting, breath by breath, the triggering and cycling mechanisms. ${ }^{23}$ Table 2 shows the configuration of the rise time and the inspiratory trigger sensitivity, which was set to the minimum value on all ventilators to prevent the occurrence of auto-triggering. ${ }^{15}$

\section{Measurements and Outcomes}

The primary outcomes assessed were inspiratory trigger delay and expiratory trigger asynchrony times. Inspiratory trigger delay was defined as the time from the onset of muscle effort (negative deflection of the $\mathrm{P}_{\text {mus }}$ ) to the beginning of the effective supply of inspiratory flow (positive deflection of the flow curve). ${ }^{16}$ Expiratory trigger delay was defined as the time from the instant of ventilator cycling to the end of muscle effort (ie, the moment at which the $\mathrm{P}_{\mathrm{mus}}$ returned to baseline). The expiratory trigger delay was classified as delayed cycling when the ventilator cycled after the end of the effort and as premature cycling when the ventilator cycled before the end of the
Table 2. Inspiratory Trigger Sensitivity and Pressure Rise Time for the Mechanical Ventilators Studied

\begin{tabular}{lll}
\hline \hline \multicolumn{1}{c}{ Ventilator/Mode } & $\begin{array}{c}\text { Inspiratory } \\
\text { Trigger }\end{array}$ & \multicolumn{1}{c}{ Rise Time } \\
\hline Esprit V1000 & $-2 \mathrm{~cm} \mathrm{H}_{2} \mathrm{O}$ & $0.2 \mathrm{~s}$ \\
DX 3012 & $-2 \mathrm{~cm} \mathrm{H}_{2} \mathrm{O}$ & Second fastest value \\
Evita IV & $3 \mathrm{~L} / \mathrm{min}^{2}$ & $0.2 \mathrm{~s}$ \\
Servo-i & $-2 \mathrm{~cm} \mathrm{H}_{2} \mathrm{O}$ & $0.2 \mathrm{~s}$ \\
Puritan Bennett 840 & $-2 \mathrm{~cm} \mathrm{H}_{2} \mathrm{O}$ & 95 and $100 \%$ of \\
& & the minimum \\
Puritan Bennett 840, PAV+ & $-2 \mathrm{~cm} \mathrm{H}_{2} \mathrm{O}$ & NA \\
Trilogy 100 & $3 \mathrm{~L} / \mathrm{min}$ & Second fastest value \\
Trilogy 100, Auto-Trak & $\mathrm{NA}$ & Second fastest value \\
& & \\
PAV+ = proportional assist ventilation plus & \\
NA = not available & & \\
\hline
\end{tabular}

effort. Auto-triggering was defined as a cycle delivered by the ventilator without a muscle effort (negative deflection of the $\mathrm{P}_{\text {mus }}$ ), indicating that the ventilator delivered a breath that was not triggered by the lung simulator. The ventilator inspiratory time $\left(\mathrm{T}_{\mathrm{I}}\right)$ was defined as the time from the start of the delivery of the $\mathrm{V}_{\mathrm{T}}$ to the lung simulator to the moment at which the $\mathrm{V}_{\mathrm{T}}$ reaches its maximum value.1,20,24 The $\mathrm{V}_{\mathrm{T}}$ and flow values were obtained with the ASL 5000 software (LabVIEW, National Instruments, Austin, Texas), and auto-PEEP values were measured by software analysis of the flow-time curve (see the supplementary materials at http://www.rcjournal.com).

After the mechanical ventilatory support had been stabilized in each experimental setting, 20 representative cycles were collected for offline analysis by the ASL 5000 software. The effective effort and ventilator $T_{I}$ were measured. The results are presented as means and SD values. Considering the stability of the mechanical model and its almost negligible variability, we chose to make nominal comparisons between the obtained values without conducting comparative statistical tests. ${ }^{15}$ The variation in $\mathrm{V}_{\mathrm{T}}$ was compared among the mean values obtained with conventional PSV on 5 ventilators (Esprit V1000, DX 3012, Evita IV, Servo-i and Puritan Bennett 840), those measured with the Trilogy ventilator (with and without AutoTrak), and those obtained in the PAV + mode of the $\mathrm{Pu}$ ritan Bennett 840 ventilator. Differences that were considered potentially clinically relevant were highlighted and discussed.

\section{Results}

We constructed 96 experimental scenarios by combining 8 ventilator modes with 3 types of respiratory mechanics profiles and 4 effort values. Simulation of effort values of 1.5 and $2.0 \mathrm{~s}$ in the restrictive profile in PAV+ 



Fig. 1. Inspiratory trigger delay (ms), according to the duration of effort, in normal (A), obstructive (B), and restrictive (C) respiratory mechanics profiles. The horizontal lines mark the 100-ms threshold, which is considered clinically significant. PAV $+=$ proportional assist ventilation plus, Trilogy AT = Trilogy with Auto-Trak.

mode was not feasible because the ventilator failed to activate that mode in the configuration. It is important to mention that despite the effort configuration in the simulator, we observed that the effective mechanical effort was slightly longer $(0.6,1.07,1.59$, and $2.12 \mathrm{~s})$.

The inspiratory trigger delay was shorter in the normal respiratory mechanics profile than in the obstructive and restrictive profiles, peaking (at $160 \mathrm{~ms}$ ) in the obstructive profile with a effort of $2.0 \mathrm{~s}$ (Fig. 1). The PAV+ mode had the shortest inspiratory trigger delay. With and without Auto-Trak, the Trilogy ventilator achieved a minimum inspiratory trigger delay at all of the inspiratory times, except in the restrictive and obstructive profiles, for which the Trilogy without Auto-Trak achieved an inspiratory trigger delay only at an inspiratory time of $2.0 \mathrm{~s}$.

The flow waveforms in the PSV and PAV + modes were recorded for the obstructive and restrictive profiles (Fig. 2). Most of the ventilators did not show significant expiratory trigger asynchrony at effort values of 1.0 and $1.5 \mathrm{~s}$ for the normal and obstructive respiratory mechanics profiles, compared with 0.5 and $1.0 \mathrm{~s}$ for the restrictive profile (Fig. 3). Expiratory trigger asynchrony (delayed cycling) was predominantly observed in the obstructive profile, whereas premature cycling was mainly seen in the restrictive profile, especially at effort values of 1.5 and $2.0 \mathrm{~s}$.

The PAV + mode was associated with longer cycling delays than were the other ventilation modes, especially for the obstructive profile and higher effort values. However, the PAV + mode showed better synchrony at effort values of 0.5 and $1.0 \mathrm{~s}$ in the restrictive profile. The PAV+ mode and the 2 Trilogy ventilation modes (with and without Auto-Trak) were associated with $\mathrm{V}_{\mathrm{T}}$ values that were lower than those obtained in the PSV mode (Fig. 4).

\section{Discussion}

The main outcome measures evaluated in the present study were the effort value, respiratory mechanics profile, ventilation mode, and type of ventilator-influenced mechanical ventilation asynchrony. Prolonged effort increased premature cycling, whereas a shorter effort was associated with delayed cycling, regardless of the type of ventilator or circuit. The obstructive respiratory mechanics profile favored delayed cycling, whereas the restrictive profile was associated with premature cycling, regardless of the ventilator type or mode. Although the PAV + mode prevented premature cycling in most situations, it was associated with delayed cycling in the obstructive profile. The $\mathrm{PAV}+$ mode also delivered lower $\mathrm{V}_{\mathrm{T}}$ values, better inspiratory time synchrony with muscle effort, and shorter inspiratory trigger delay than did PSV. The portable single-limb circuit ventilator showed better inspiratory triggering than did the conventional ICU ventilators.

To our knowledge, this is the first study to specifically address mechanical ventilation asynchrony by evaluating different effort values in the PSV, PAV+, and Auto-Trak function. Some clinical studies have evaluated patientventilator asynchrony in subjects with COPD and in those undergoing resolution of ARDS. Such patients might partially correspond to the obstructive and restrictive models used in the present study. $22,25,26$ Other investigators have 




Fig. 2. Representative flow waveforms (in L/min) on the left axis (solid line) and respiratory muscle pressure $\left(P_{\text {mus }}\right.$, in $\left.\mathrm{cm} \mathrm{H}_{2} \mathrm{O}\right)$ on the right axis (dashed line) over time for the pressure support ventilation (PSV) and proportional assist ventilation plus (PAV + ) modes in the obstructive and restrictive respiratory mechanics profiles.

found that delayed expiratory triggering (delayed cycling) and ineffective efforts are common during PSV in subjects with $\mathrm{COPD}^{20}$ and that premature cycling is common in subjects with ARDS, especially at a threshold of $30 \%$ of peak inspiratory flow. ${ }^{26}$ The results of the present study are concordant with those observational data. ${ }^{22,26} \mathrm{It}$ is noteworthy that, in our model, delayed cycling occurred in PSV, even when the cycling threshold was adjusted to $45 \%$ of the peak inspiratory flow.

During PSV, perfect synchrony occurs only if the effort coincides with the ventilator $T_{I}$, which is influenced by the cycling-off criterion. ${ }^{27,28}$ In PSV, cycling asynchrony is influenced by respiratory mechanics: The combination of high airway resistance with a short effort predisposes to delayed cycling, whereas restrictive respiratory mechanics with a long effort predisposes to premature cycling. As effort increases, asynchrony tends to switch from delayed to premature cycling, assuming that all other variables remain constant. That phenomenon was clearly demonstrated in our results. The same phenomenon led other investigators to build an algorithm for PSV cycling, in which the cycling-off criterion is periodically readjusted by a closed-loop system instead of being arbitrarily chosen by the operator of the ventilator. ${ }^{22,29}$ That algorithm has been tested in a specific ventilator in a small number of subjects. ${ }^{25}$ When compared with a fixed cycling criterion of $5 \%$ of peak inspiratory flow, the use of the automatic, real-time-adjusted cycling criterion improved patient-ventilator synchrony.

Clinical comparisons of PSV versus PAV + have shown that the latter improves patient-ventilator synchrony. ${ }^{5}$ In $\mathrm{PAV}+$ mode, cycling asynchrony is less likely to occur, because the cycling criterion is an absolute value of flow, typically $3 \mathrm{~L} / \mathrm{min}$, and, as patient effort starts to decrease, flow delivery decelerates; when the cycling criterion is met, the ventilator transitions to exhalation, and premature cycling is avoided in most situations. In the present study, $\mathrm{PAV}+$ prevented premature cycling with normal and obstructive patterns of respiratory mechanics and long effort, whereas PSV did not. The PAV+ mode also delivered inspiratory flow that better matched inspiration effort, which was not the case for PSV.

We also showed that PAV+ increases the risk of delayed cycling, and that effort may be shorter than ventilator $T_{I}$ in this mode. ${ }^{5,12}$ Confirming the findings of previous studies, ${ }^{5,10}$ we found that PAV+ resulted in $\mathrm{V}_{\mathrm{T}}$ values lower than those obtained with PSV. Lower $V_{T}$ values can reduce the risk of air trapping and ventilatory overassistance.

The Auto-Trak function applies multiple algorithms derived from flow, volume, and pressure measurements during the respiratory cycle to trigger and cycle the ventilator. The shape signal is one of those algorithms. It is a mech- 
Influence of Simulated Variables on Asynchrony in PSV and PAV
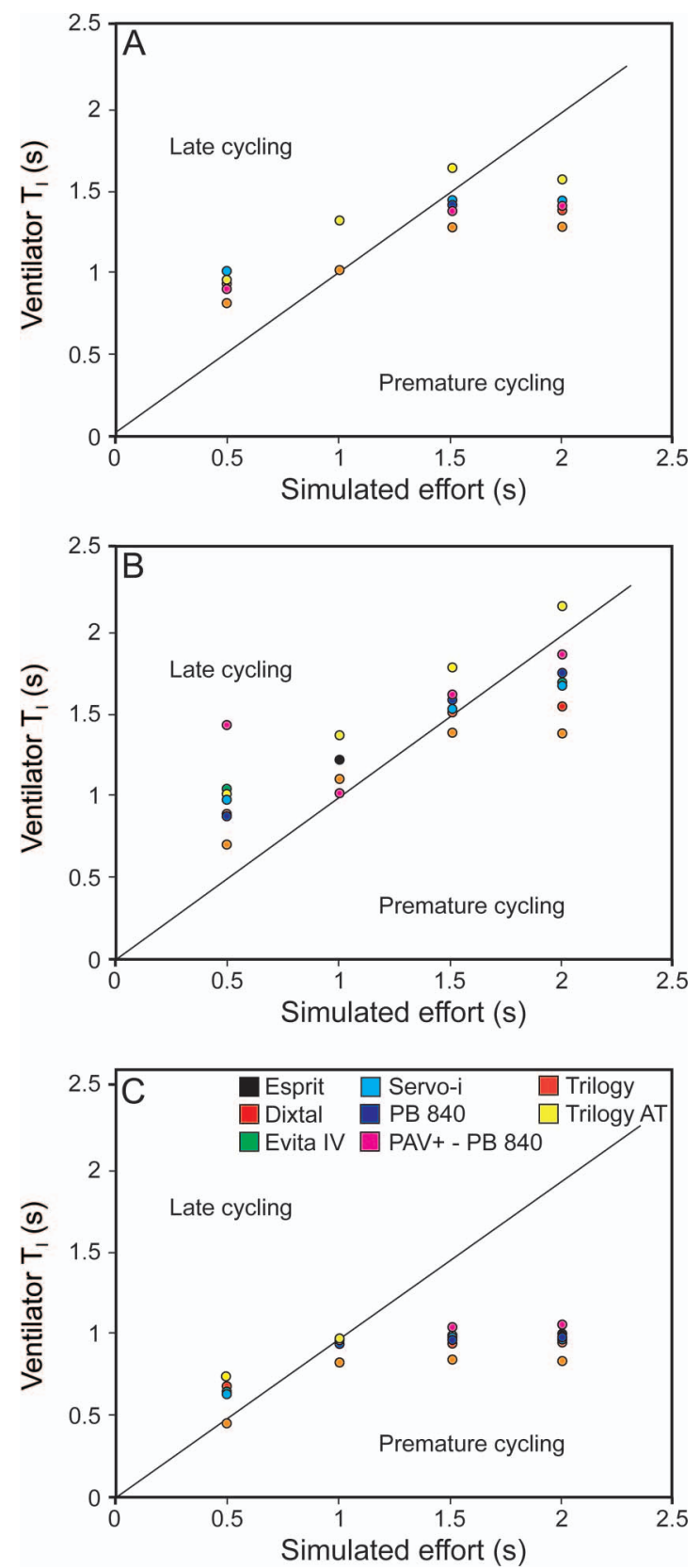

Fig. 3. The correlation between the ventilator inspiratory time ( $T_{1}$ ventilator) and duration of effort in the normal $(A)$, obstructive $(B)$, and restrictive $(C)$ respiratory mechanics profiles. $\mathrm{PAV}+=$ proportional assist ventilation plus, Trilogy AT $=$ Trilogy with Auto-Trak.

anism that works for both triggering and cycling of the ventilator. This is a virtual waveform of the real flow curve of the previous cycle, except it is $15 \mathrm{~L} / \mathrm{min}$ less and $300 \mathrm{~ms}$ delayed in relation to the real cycle. When the patient makes a respiratory effort and the real flow curve crosses the virtual signal, inspiratory assistance is automatically triggered. Similarly, when the effort ceases or expiratory effort occurs, the flow waveform changes its slope and intersects with the virtual waveform, and cycling occurs. ${ }^{23}$
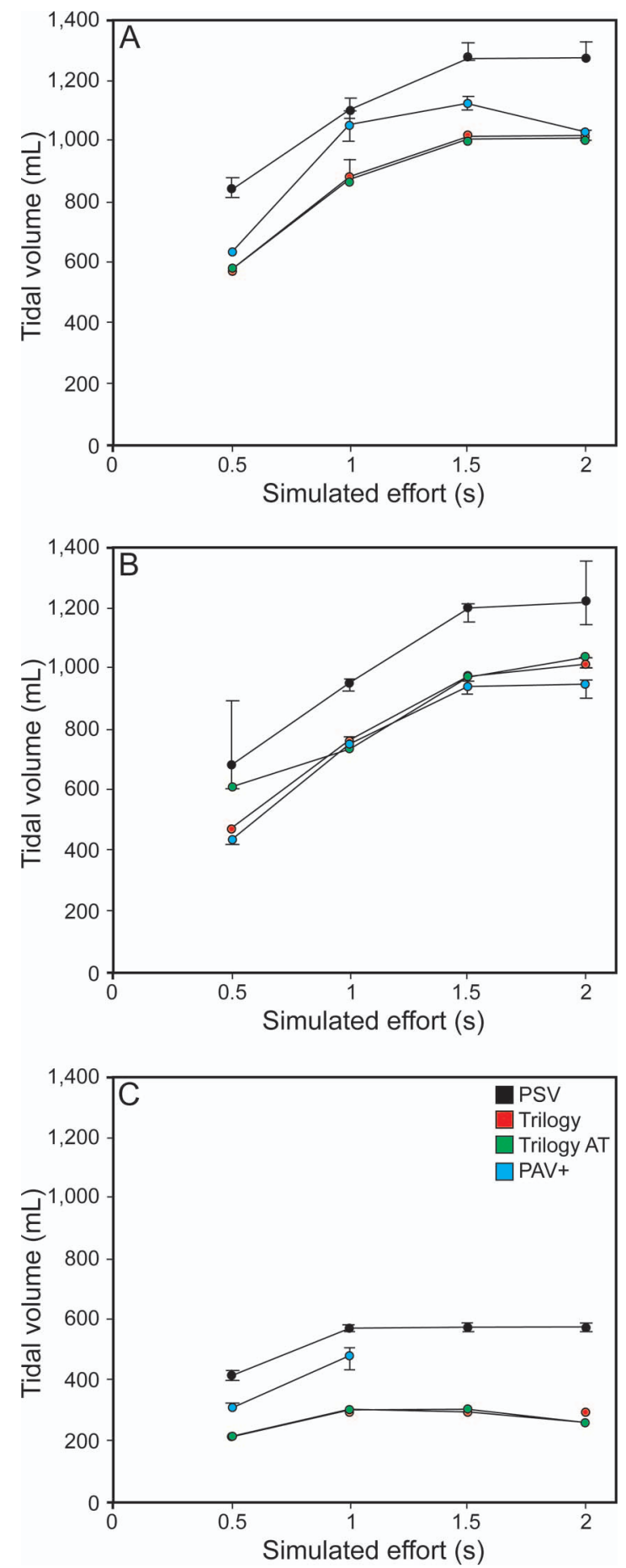

Fig. 4. Tidal volume $\left(\mathrm{V}_{\mathrm{T}}\right)$, according to the duration of effort, in normal $(A)$, obstructive $(B)$, and restrictive $(C)$ respiratory mechanics profiles. Simulation of effort at 1.5 and $2 \mathrm{~s}$ in the restrictive profile was not feasible in PAV+ mode because the ventilator failed to activate that mode in the configuration. PSV $=$ pressure support ventilation, $\mathrm{PAV}+=$ proportional assist ventilation plus, Trilogy AT = Trilogy with Auto-Trak. 


\section{Influence of Simulated Variables on Asynchrony in PSV and PAV}

In comparison with PSV with a fixed cycling-off criterion, the virtual waveform has been shown to decrease patient triggering effort and to improve ventilator performance. ${ }^{30}$ However, the virtual waveform system can also generate asynchrony. In a previous study conducted by our research group, Auto-Trak and manual adjustments of the cyclingoff criteria showed similar results with respect to patientventilator synchrony and patient comfort. ${ }^{23}$ In the present study, the use of Auto-Trak in a single-limb circuit ventilator showed similar results to conventional settings concerning cycling asynchrony.

Previous studies have shown that an inspiratory trigger delay of $<100 \mathrm{~ms}$ has negligible clinical effects. ${ }^{31,32}$ In the present study, we found that the inspiratory trigger delay was below that threshold for all ventilators when the respiratory mechanics were normal or restrictive, although it was above the threshold when the respiratory mechanics profile was obstructive, the difference being due, in part, to the presence of auto-PEEP. The PAV+ mode significantly reduced inspiratory trigger delay. This is in contrast with previous findings that the triggering function is not influenced by the ventilation mode $^{12}$ and might be related to the fact that the lower $\mathrm{V}_{\mathrm{T}}$ values in PAV+ mode reduce auto-PEEP. The use of Auto-Trak was also associated with a significant reduction in the inspiratory trigger delay and eliminated auto-triggering asynchrony.

This study has some limitations. We used a mechanical model of the respiratory system, and our results should be confirmed in real patients. Nevertheless, given the difficulties of studying the determinants of patient-ventilator interaction at the bedside, the lung simulator enabled us to conduct such investigations, showing good reproducibility and reliability, as well as to avoid risks for patients in clinical investigations. ${ }^{33}$ In addition, the $\mathrm{P}_{\text {mus }}$ employed varied in duration but not in intensity. Furthermore, we tested only pressure triggering (not flow triggering). Moreover, the pressurization time (rise time function), which is known to influence mechanical ventilation synchrony, ${ }^{16,33}$ was not modified in PSV mode. Finally, the experimental setting did not include simulation of cardiogenic oscillations, which could cause auto-triggering.

Our findings have practical implications. Although the results highlight the limitations of the PSV and PAV+ modes in preventing mechanical ventilation asynchrony, $\mathrm{PAV}+$ was superior in that it offered inspiratory support proportional to respiratory muscle effort, thus avoiding premature cycling, excessive $\mathrm{V}_{\mathrm{T}}$ values, and overassistance. The Auto-Trak system was also associated with less asynchrony in triggering and cycling, because it automatically adjusts both and simplifies the operation of the ventilator.

\section{Conclusions}

Mechanical ventilation asynchrony is influenced by the effort, respiratory mechanics, ventilator type, and ventilation mode. In the PSV mode, delayed cycling was more common with shorter effort in the obstructive respiratory mechanics profile, whereas premature cycling was more common with longer effort and the restrictive profile. The Auto-Trak system with the single-limb circuit ventilator improves triggering function. PAV + can prevent premature cycling but not delayed cycling, especially in the obstructive respiratory mechanics profile, and is associated with lower $\mathrm{V}_{\mathrm{T}}$ values than is PSV. Further clinical investigations are needed to confirm these experimental findings.

\section{REFERENCES}

1. Thille AW, Rodriguez P, Cabello B, Lellouche F, Brochard L. Patient-ventilator asynchrony during assisted mechanical ventilation. Intensive Care Med 2006;32(10):1515-1522.

2. Kondili E, Prinianakis G, Georgopoulos D. Patient-ventilator interaction. Br J Anaesth 2003;91(1):106-119.

3. Pierson DJ. Patient-ventilator interaction. Respir Care 2011;56(2): 214-228.

4. Blanch L, Villagra A, Sales B, Montanya J, Lucangelo U, Luján M, et al. Asynchronies during mechanical ventilation are associated with mortality. Intensive Care Med 2015;41(4):633-641.

5. Costa R, Spinazzola G, Cipriani F, Ferrone G, Festa O, Arcangeli A, et al. A physiologic comparison of proportional assist ventilation with load-adjustable gain factors $(\mathrm{PAV}+)$ versus pressure support ventilation (PSV). Intensive Care Med 2011;37(9):1494-500.

6. Alexopoulou C, Kondili E, Plataki M, Georgopoulos D. Patientventilator synchrony and sleep quality with proportional assist and pressure support ventilation. Intensive Care Med 2013;39(6):10401047.

7. Thille AW, Cabello B, Galia F, Lyazidi A, Brochard L. Reduction of patient-ventilator asynchrony by reducing tidal volume during pressure-support ventilation. Intensive Care Med 2008;34(8):1477-1486.

8. Younes M. Proportional assist ventilation, a new approach to ventilatory support: theory. Am Rev Respir Dis 1992;145(1):114-120.

9. Kondili E, Prinianakis G, Alexopoulou C, Vakouti E, Klimathianaki $\mathrm{M}$, Georgopoulos D. Respiratory load compensation during mechanical ventilation-proportional assist ventilation with load-adjustable gain factors versus pressure support. Intensive Care Med 2006;32(5): 692-699.

10. Bosma K, Ferreyra G, Ambrogio C, Pasero D, Mirabella L, Braghiroli A, et al. Patient-ventilator interaction and sleep in mechanically ventilated patients; pressure support versus proportional assist ventilation. Crit Care Med 2007;35(4):1048-1054.

11. Grasso S, Puntillo F, Mascia L, Ancona G, Fiore T, Bruno F, et al. Compensation for increase in respiratory workload during mechanical ventilation: pressure-support versus proportional-assist ventilation. Am J Respir Crit Care Med 2000;161(3 Pt 1):819-26.

12. Kacmarek RM. Proportional assist ventilation and neurally adjusted ventilatory assist. Respir Care 2011;56(2):140-148; discussion 149152

13. Nava S, Bruschi C, Rubini F, Palo A, Iotti G, Braschi A. Respiratory response and inspiratory effort during pressure support ventilation in COPD patients. Intensive Care Med 1995;21(11):871-879. 


\section{Influence of Simulated Variables on Asynchrony in PSV and PAV}

14. Battisti A, Tassaux D, Janssens JP, Michotte JB, Jaber S, Jolliet P. Performance characteristics of 10 home mechanical ventilators in pressure-support mode: a comparative bench study. Chest 2005; 127(5):1784-1792.

15. Ferreira JC, Chipman DW, Hill NS, Kacmarek RM. Bilevel vs ICU ventilators providing noninvasive ventilation: effect of system leaks: a COPD lung model comparison. Chest 2009;136(2):448-456.

16. Murata S, Yokoyama K, Sakamoto Y, Yamashita K, Oto J, Imanaka $\mathrm{H}$, Nishimura M. Effects of inspiratory rise time on triggering work load during pressure-support ventilation: a lung model study. Respir Care 2010;55(7):878-884.

17. Ferreira JC, Chipman DW, Hill NS, Kacmarek RM. Trigger performance of mid-level ICU mechanical ventilators during assisted ventilation: a bench study. Intensive Care Med 2008;34(9):1669-1675.

18. Carteaux G, Lyazidi A, Cordoba-Izquierdo A, Vignaux L, Jolliet P, Thille AW, et al. Patient-ventilator asynchrony during noninvasive ventilation: a bench and clinical study. Chest 2012;142(2):367-376.

19. IngMar Medical. ASL 5000 - Active Servo Lung computerized breathing simulator and ventilator test instrument user's manual. Pittsburgh, Pennsylvania: IngMar Medical; 2006.

20. Costa R, Navalesi P, Spinazzola G, Ferrone G, Pellegrini A, Cavaliere $\mathrm{F}$, et al. Influence of ventilator settings on patient-ventilator synchrony during pressure support ventilation with different interfaces. Intensive Care Med 2010;36(8):1363-1370.

21. Papazian L, Forel JM, Gacouin A, Penot-Ragon C, Perrin G, Loundou A, et al. Neuromuscular blockers in early acute respiratory distress syndrome. N Engl J Med 2010;363(12):1107-1116.

22. Tassaux D, Gainnier M, Battisti A, Jolliet P. Impact of expiratory trigger setting on delayed cycling and inspiratory muscle workload. Am J Respir Crit Care Med 2005;172(10):1283-1289.

23. Vasconcelos Rdos S, Melo LH, Sales RP, Marinho LS, Deulefeu FC, Reis RC, et al. Effect of an automatic triggering and cycling system on comfort and patient-ventilator synchrony during pressure support ventilation. Respiration 2013;86(6):497-503.
24. Thille AW, Lyazidi A, Richard JC, Galia F, Brochard L. A bench study of intensive-care-unit ventilators: new versus old and turbinebased versus compressed gas-based ventilators. Intensive Care Med 2009;35(8):1368-1376.

25. Hoff FC, Tucci MR, Amato MB, Santos LJ, Victorino JA. Cycling-off modes during pressure support ventilation: effects on breathing pattern, patient effort, and comfort. J Crit Care 2014; 29(3):380-385.

26. Tokioka H, Tanaka T, Ishizu T, Fukushima T, Iwaki T, Nakamura Y, Kosogabe Y. The effect of breath termination criterion on breathing patterns and the work of breathing during pressure support ventilation. Anesth Analg 2001;92(1):161-165.

27. Chiumello D, Colombo A, Algieri I. Cycling-off criteria during pressure support ventilation: what do we have to monitor? J Crit Care 2014;29(3):457-458

28. Yamada Y, Du HL. Analysis of the mechanisms of expiratory asynchrony in pressure support ventilation: a mathematical approach. J Appl Physiol 2000;88(6):2143-2150.

29. Du HL, Amato MB, Yamada Y. Automation of expiratory trigger sensitivity in pressure support ventilation. Respir Care Clin N Am 2001;7(3):503-517, x.

30. Prinianakis G, Kondili E, Georgopoulos D. Effects of the flow waveform method of triggering and cycling on patient-ventilator interaction during pressure support. Intensive Care Med 2003;29(11):19501959.

31. Kondili E, Xirouchaki N, Georgopoulos D. Modulation and treatment of patient-ventilator dyssynchrony. Curr Opin Crit Care 2007; 13(1):84-89.

32. Vignaux L, Tassaux D, Jolliet P. Performance of noninvasive ventilation modes on ICU ventilators during pressure support: a bench model study. Intensive Care Med 2007;33(8):1444-1451.

33. Aslanian P, El Atrous S, Isabey D, Valente E, Corsi D, Harf A, et al. Effects of flow triggering on breathing effort during partial ventilatory support. Am J Respir Crit Care Med 1998;157(1):135-143. 